\begin{tabular}{|l|l|}
\hline $\begin{array}{l}\text { Postprint } \\
\text { Version }\end{array}$ & 1.0 \\
\hline Journal website & http://eur.sagepub.com/cgi/content/abstract/15/4/307 \\
\hline Pubmed link & $10.1177 / 0969776408095107$ \\
\hline DOI & \\
\hline
\end{tabular}

This is a NIVEL certified Post Print, more info at http://www.nivel.eu

\title{
URBAN-RURAL HEALTH DIFFERENCES AND THE AVAILABILITY OF GREEN SPACE
}

\author{
R.A.VERHEIJ, J. MAAS AND P.P. GROENEWEGEN NETHERLANDS INSTITUTE FOR HEALTH SERVICES \\ RESEARCH, UTRECHT
}

\begin{abstract}
It is argued that urban-rural health differences, which are found in many studies, may be at least partially associated with the availability of green space. Until recently there was only limited evidence from experimental research for this relationship, but recent large-scale epidemiological work found new evidence for the association between urban-rural health differences and availability of green space. It is argued that this would fit in with the theories of the classic urban sociologists Wirth and Milgram and the theories of environmental psychologists like Kaplan and Kaplan.

The availability of new evidence and the fit into the classic theories would also justify renewed attention for green space in urban planning.
\end{abstract}

\section{INTRODUCTION}

According to UN reports, the urban population now amounts to 50 percent and will rise to about 75 percent by 2030 (Population Division of the Department of Economic and Social Affairs of the United Nations, 2007). It is therefore increasingly important that we understand the impact of living in cities on people's health and well-being.

Differences in health between urban and rural areas have been an intriguing subject of study for many sociologists, geographers, and psychologists for many decades and in many countries. Urbanicity also plays an important role in our daily lives.

Indeed, the urban-rural divide is one of the key characteristics according to which we define ourselves. However, thus far, many attempts have been made to tease out statistically the underlying reasons for the urban-rural health divide, many of them without success.

In this article we will first give a short description of urban-rural health differences in the Netherlands and in other countries. We go on to discuss the existing theories which try to explain the urban-rural health theories. After discussing these theories, we move on to recent findings from epidemiological research in the Netherlands, suggesting that green space may be important in explaining urban-rural health differences.

\section{Urban-rural health differences}

The Netherlands is one of the most densely populated countries in the world. It is also a very small country with about $16 \mathrm{~m}$ inhabitants and maximum dimensions of about $350 \mathrm{~km}$ by $250 \mathrm{~km}$. Visitors from more sparsely populated parts of the world like Australia, the US and even the UK often regard it as one big urban conglomerate. However, even within this setting there are marked health differences between urban and rural parts of the country.

This can for example be illustrated by results from a health interview survey in a representative sample of the Dutch population in 2001. Figure 1 shows the crude health differences between urban and rural areas. Data are derived from the Second National Survey of General Practice (Westert et al., 2005). Urbanicity is based on the number of addresses per square kilometre (Den Dulk et al., 1992). 
It is clear that people in the most urban areas feel less healthy than their rural counterparts. Similar results were found by Otten and Frenken (2006).

Such differences remain if results are controlled for demographic factors. Janssen-Janssen et al. (2001) found that residents of the most urban areas have an 18 percent higher probability of experiencing their health status as 'less than good', controlling for age, gender, level of education and ethnicity.

The urban-rural gradient seems to be even stronger with respect to mental health problems.

Figure 2 shows the distribution of the probability of having a mental illness across degrees of urbanicity as measured by the general health questionnaire (GHQ) (Goldberg and Williams, 1988). Here the urban-rural difference is even bigger: the number of people with a high probability of mental health problems in the most urban category is twice as high as that in the most rural category.

Analyses of chronic conditions and acute health problems such as common colds and sprained ankles show much smaller differences between urban and rural areas (results not shown).

Similar comparisons have been made in other countries. There is a tendency in western European countries for urban areas to be found less healthy.

However, on a global scale it is most probable that there is essentially a U-shaped relation between urbanicity and health, with the most urban and densely populated areas on the left and the most remote and sparsely populated areas on the right.

This U-shaped relationship was put forward by Barnett et al. (2001) on the basis of their study on geographical variations in limiting long-term illness in the South West of England. Such a U-shaped relationship would explain on the one hand that research in, for example, Australia reports a rural health disadvantage (Campbell et al., 2006), as these studies will often be looking at the right side of the U. On the other hand, it would explain the urban disadvantage that is frequently found in western European studies (Campbell et al., 1991; Kruger et al., 1995; Levin, 2003) where remote rural areas are often lacking.

The Netherlands is clearly a country where remote rural areas are absent. Only 0.6 percent of the population live more than 30 minutes away from the nearest hospital with acute care facilities and 55 percent live within 10 minutes' travel-time (Giesbers, 2006).

After this brief illustration of the urban-rural health differences in the Netherlands we can return to the question of what it is about urban areas that causes these differences.

\section{[FIGURE 1][FIGURE 2]}

\section{'Urbanism as a way of life'}

Louis Wirth was one of the first in trying to describe the nature of modern cities in a systematic way. His classic article, 'Urbanism as a Way of Life', was published in the 1930s in the American Journal of Sociology (Wirth, 1938) and can be regarded as one of the most influential papers in urban sociology. A Google search reveals that this article has been cited by 422 colleagues, which is probably a vast underestimate as we don't think Google looks back more than 10 years and only considers electronically published papers. Wirth was one of the first who tried to define what was special about cities: 'cities are large, densely populated, settlements of socially heterogeneous individuals'. Wirth's article is about the way these characteristics influence the way of life of city residents, and at the beginning of his article he recognizes the fact that people have not always lived in cities and that 'the influences it exerts upon the modes of life should not be able to wipe out completely the previously dominant modes of human association'. In other words, people inherit their evolutionary past. This notion is not without meaning in modern-day urban areas. Especially in developing countries, a large portion of the urban growth rates is the result of rural to urban migration.

Wirth's article had many critics. One of them was Stanley Milgram (Milgram 1970). In his article 'The Experience of Living in Cities', Milgram agreed with Wirth's definition of urbanicity, but something was lacking: the way size, density and heterogeneity influence the experience of daily life in cities. When it comes down to experience, there's eventfulness, variety, the possibility of choice, on the one hand.

But on the other hand, the demographic circumstances invoke a number of processes or strategies to avoid psychological overload. This can be interpreted as a consequence of our evolutionary background as our species is not (yet?) equipped to absorb all input that we encounter in modern city life. Because of that we have to develop strategies to avoid psychological overload. Milgram lists a number of these strategies: we 
have to allocate less time to each input; we have to disregard low priority inputs; we have to filter out high intensity inputs, and we have to filter the number of inputs in an economical way, for example by introducing specialized institutions and regulations. It also leads to restriction of involvement and by limiting the 'span of sympathy' to anonymity and lack of civilities.

One of the key messages of Milgram is that urban living is more stressful, in spite of all possible mechanisms of coping with psychological overload.

Or perhaps even because of these coping mechanisms.

\section{Explaining urban-rural differences}

After Wirth (and Milgram), urban-rural differences have been studied extensively by others. In this literature, two main hypotheses prevail that may contribute to urban-rural differences in health and well-being: the breeder and the drift hypotheses (Verheij, 1996).

According to the drift hypothesis urban-rural health differences are caused by selective migration:

- Ill people move to (or from) specific places (direct selection); more susceptible people move to urban areas (indirect selection).

According to the breeder hypothesis, urban-rural health differences are caused by:

- Exposure to environmental factors that are specifically related to cities, such as: pollution, busy traffic, poor housing quality, lower levels of health service provision.

- Behaviour: smoking, excessive drinking are more prevalent in urban areas. We will briefly discuss these mechanisms below and see how green space might fit into these mechanisms.

\section{Selective migration}

Selective migration to or retention in particular living environments might explain part of the relationship between urbanicity and health. In the case of indirect selection, city environments would attract distinctive higher risk groups. Indirect selection occurs when people with certain characteristics, such as a high income, that are related to well-being and health can afford to live in a favourable environment. Migration flows in general are related to such socio-demographic characteristics as age, income and education.

Consequently, indirect selection might play a role in explaining relationships between urbanicity and health. It is therefore important to take into account and control for the possibility of selection.

In the case of direct selection, urban environments attract ill people. Direct selection occurs when people's well-being influences their chances of living in a favourable environment.

In cross-sectional studies we can only deal with indirect selection effects by controlling for all possible predisposing factors like demographic characteristics, socio-economic status, smoking and drinking. Longitudinal studies are needed to control for direct selection.

Not surprisingly, there is only little research on the effects of direct selection on the spatial distribution of health and the studies that do exist differ in their outcomes. Some longitudinal studies indicate that migration is selective for the healthy, other studies suggest that migration is selective for the unhealthy. For example Norman et al. conclude in a study in England and Wales that migrants are generally healthier than non-migrants and that the minority of migrants to more deprived areas are generally less healthy (Norman et al., 2005).

However, an Australian study showed that migrants are generally less healthy (Larson et al., 2004).

Either way, these results indicate that migration can play an important role in the absolute health differences between geographical areas.

However, in a Dutch study, Verheij et al.

concluded that it was not likely that selective migration played a significant role in explaining the urbanrural health differences that remain when socio-economic and demographic characteristics are statistically controlled for (Verheij et al., 1998).

Moreover, it was found in a Dutch longitudinal study with 10 years' follow-up that selective migration will hardly contribute to neighbourhood inequalities in health and health-related behaviour (Van Lenthe et al., 2007). A similar conclusion was found in a study in Sweden (Lewis et al., 1992). The incidence of schizophrenia was 1.65 times higher among men brought up in cities than in those who had had a rural upbringing. This association persisted despite adjustment for other factors associated with city life such as cannabis use, parental divorce, and family history of psychiatric disorder. These findings contradict the widely held notion that people with schizophrenia drift into cities at the beginning of their illness. Lewis concludes that undetermined environmental factors found in cities increase the risk of schizophrenia. 
Verheij, R.A., Maas, J., Groenewegen, P.P. Urban-rural health differences and the availability of green space. European Urban and Regional Studies: 2008, 15(4), 307-316

\section{Behaviour}

The second possible mechanism that might explain urban-rural health differences is the

behavioural mechanism. In the Netherlands, for example, it was found that heavy smoking, heavy drinking and being overweight are more common in the most urban areas (Janssen-Janssen et al., 2001).

Differences in the level of physical activity have also been found. In the most urban areas 48.1 percent of the people do not meet the Dutch public health recommendation for physical activity as opposed to 36.7 percent in rural areas (Lindert et al., 2004). However, recent data show that there is only a small urbanrural difference in the number of people who have at least 30 minutes of moderately intensive physical activity a day (Statistics Netherlands, 2007).

These results suggest that the health status of urban populations will even become worse in the years to come, as smoking and being overweight are important risk factors for diabetes and heart diseases. However, a recent study in the city of Amsterdam showed that the level of physical activity was higher in the more densely populated areas with few free parking spaces and relatively many shops within walking distance (Den Hertog et al., 2006).

In the US, studies on the walkability of neighbourhoods showed similar results (e.g. Frank et al., 2007). Rural areas aren't what they used to be either.

Though rural residents generally drink less than urban residents, for young people the reverse is true: young people in rural areas tend to drink more than their urban counterparts (Schellingerhout and Van Campen, 2006). Similar tendencies seem to exist in other countries (Mitura and Bollman, 2004).

Exposure and behaviour are clearly interlinked as people are exposed to other people's behaviour (e.g. passive smoking, unsafe driving).

\section{Exposure}

The most obvious examples of exposure are traffic noise and pollution which are more common in urban areas. However, pollution is not restricted to urban areas. The risks associated with agriculture are also well documented. Poisoning and cancer as a result of the use of pesticides and accidents with agricultural machinery have been frequently reported.

Exposure to pollution may be responsible for part of the urban-rural health differences. However, it has been difficult to distinguish the effects from a more general 'urban' effect. An attempt to do this was made in a Danish study (Pedersen and Mortensen, 2006). They found that the cause(s) or exposure(s) responsible for the urban-rural differences in schizophrenia risk were more closely related to the degree of urbanization than to the geographical distance to the nearest major road (Pedersen and Mortensen, 2006). Trafficrelated exposures might thus be less likely explanations for the urban-rural differences in schizophrenia risk.

Exposure to stress is another factor that has been put forward as an explanation for the urban-rural health differences. According to this hypothesis, urban residents are more frequently and more severely confronted with stressors than rural residents, resulting in higher levels of psychiatric morbidity (Verheij, 1996).

\section{Nature, health and urbanicity}

The effect of urbanicity on people's health seems to be quite resistant to attempts to control for demographic, socio-economic and behavioural factors, as well as selective migration.

However, the results from a large-scale epidemiological study (Maas et al., 2006) in the Netherlands suggest that the availability of green space might be an important factor in explaining the urban-rural health differences. The results of this study confirm earlier findings in a smaller epidemiological study (de Vries et al., 2003) and indicate that the availability of green space is more strongly associated with people's perceived general health than urbanicity, controlling for age, gender, socio-economic status, job status and ethnicity. This is true for the availability of green space within a $1 \mathrm{~km}$ radius as well as within a $3 \mathrm{~km}$ radius around people's places of residence. These results suggest that the availability of green space is more than just an indicator of population density and that it adds to existing theories about urban-rural health differences.

All age groups benefit equally from green space in their living environment, although in the large cities it seems restricted to the elderly and young. Lowereducated groups benefit most from green space in their living environment. Intriguing is the fact that there is no differential effect for agricultural green space, 'real' nature or urban parks.

In sum, the study by Maas et al. (2006) shows that green space is more than just a luxury good. 
This is an important message in a country where green space becomes scarce and it has direct consequences for spatial planning, in which developing and maintaining green space should get a more central position. In urban planning since the beginning of the 20th century there has historically been awareness that green space is important. One of the most famous examples is the Abercrombie system of green belts introduced in London in 1944.

However, in the Netherlands, this awareness seems to have weakened in the last decades as many green patches of land in inner city areas have been filled in.

These studies are not the first on the relation between green space and health, but they are the first largescale epidemiological study that includes urbanicity as well as the availability of green space.

Most of the research that was published thus far was carried out on a smaller scale and in experimental settings.

\section{How does green space affect health?}

But how does it work? What mechanism would be responsible for the health effect of green space? A review by the Health Council of the Netherlands etc. (2004) shows there is growing evidence to demonstrate that natural environments are healthier than non-natural environments.

Different underlying mechanisms have been proposed. Green space may help people to recover from stress and attention fatigue, and may stimulate physical activity and facilitate social contacts.

However, strong scientific evidence has only been found for the positive effects of nature on recovery from stress and attention fatigue.

Exposure to nature has proved to have a positive effect on mood, for example, as well as concentration, self-discipline, and physiological stress. These effects were found in the field as well as under laboratory conditions and the effect occurs even after brief exposure to a picture of a nature area (Health Council of the Netherlands and Dutch Advisory Council for Research on Spatial Planning, 2004).

Different underlying theories are used to explain why green space exerts a beneficial effect on health. The most important theories concerning the influence of nature on recovery from stress and attention fatigue are Wilson's biophilia hypothesis (Wilson, 1984), Ulrich's psycho-evolutionary model (Ulrich, 1993) and Kaplan and Kaplan's Attention Restoration Theory (ART) (Kaplan and Kaplan, 1989). All these theories are based on the idea that the restorative effects of nature have an innate, evolutionary basis.

The so-called biophilia hypothesis states that human preferences towards things in nature, while refined through experience and culture, are hypothetically the product of biological evolution.

It was introduced by Wilson (Wilson, 1984).

According to Wilson, archaeological evidence tells us that for most of the $2 \mathrm{~m}$ years that homo sapiens has existed, we lived on the savannas of Africa, and subsequently those of Europe and Asia. These were vast parklike grasslands, dotted by groves and scattered trees. This environment provided food and shelter, while at the same time offering long views to detect enemies. There seems to be general agreement that our bipedal locomotion and free swinging arms have developed in this environment as they are the perfect adaptations for this type of environment. They enabled us to overlook the landscape for possible prey or enemies, and allowed us to pick fruit from trees. But not only our physics were formed in this type of environment, Wilson goes on, but also our minds. In general, those of us who were best equipped to live in this environment were best able to find the plants to eat, the water to drink and the shelter to hide. If we translate this to modern Western society, it is the reason why the real estate in Figure 3 is more sought after and expensive than the real estate in Figure 4. In Wilson's words: 'it seems that whenever people are given a free choice, they move to open tree-studded land, on prominences overlooking water'. Conversely, the absence of all this will cause stress.

In Ulrich's psycho-evolutionary model it is argued that 'particular characteristics of the environment have an early-warning function for safety and survival. As a result of an innate adaptive mechanism, the perception of these characteristics triggers positive emotional reactions. These reactions also ensure that we are attracted by natural environments' (Ulrich, 1993). According to the Attention Restoration Theory from Kaplan and Kaplan (1989), natural environments provide opportunities to distance oneself from routine activities and thoughts (being away) and they automatically attract attention without requiring any effort (soft fascination). 
Verheij, R.A., Maas, J., Groenewegen, P.P. Urban-rural health differences and the availability of green space. European Urban and Regional Studies: 2008, 15(4), 307-316

In sum, the biophilia hypothesis suggests that evolutionary processes have caused us to feel happier in a savanna-like landscape than in an inner-city neighbourhood.

\section{[FIGURE 3]}

\section{The Vitamin G project}

As said, the study by Maas et al. (2006) was the first large-scale epidemiological study showing a relation between green space and health, and particularly that this relation was stronger than the one between urbanicity and health. This project is part of a larger research programme in which the health effects of green space are investigated. This programme is called Vitamin G (in which G stands for Green).

The aim of this research programme (funded by the Netherlands Organization for Scientific Research) is to assess the relationship between the amount and type of green space in people's living environment and their health, well-being, and feelings of safety; to study the possible mechanisms behind this relationship; and to generate recommendations for health and spatial policy (Groenewegen et al., 2006).

In the near future we will investigate whether the green space effect is limited to specific diseases. This will be done on the basis of primary-care electronic medical records. The possible mechanisms behind the effect of green space will be investigated by looking at stress, physical activity, and social contacts.

Whether or not our results can be generalized to other parts of Europe (or the world) is another question we want to look into. In this respect it will be interesting to see whether the green space-health relationship is typical for a densely populated country like the Netherlands.

\section{[FIGURE 4]}

\section{EPILOGUE: PARIS RIOTS AND GREEN SPACE}

In March 2006 a Dutch newspaper reported: After the severe riots in the deprived Paris suburbs, autumn 2005, a French delegation of civil servants visited an equally deprived neighbourhood in the city of Rotterdam. However, they concluded that the situation in the Rotterdam neighbourhood was far from comparable to theirs. The French delegation commented: 'This neighbourhood has open, green spaces; this neighbourhood breathes.' (NRC-Handelsblad, 2006).

This citation illustrates that people feel that the availability of green space in people's environment matters for health and well-being. However, if we look at the two places from a satellite (Clichy sous Bois and Pendrecht), the French neighbourhood looks much greener than the Rotterdam neighbourhood. Apparently, the availability of green space might be an important factor, but it is by no means the only factor to account for geographical differences in health and well-being.

\section{ACKNOWLEDGEMENT}

This article was presented at the Sixth European Urban and Regional Studies Conference in Roskilde, Denmark in September 2006.

\section{REFERENCES}

Barnett, S., Roderick, P., Martin, D. and Diamond, I.(2001) 'A Multilevel Analysis of the Effects of Rurality and Social Deprivation on Premature Limiting Long Term Illness', Journal of Epidemiological and CommunityHealth 55: 44-51.

Campbell, D.A., Radford, J.M.C. and Burton, P. (1991) 'Unemployment Rates: an Alternative to the Jarman Index?', British Medical Journal 303: 750-3.

Campbell, A., Manoff, T. and Caffery, J. (2006) 'Rurality and Mental Health: an Australian Primary Care Study', Rural Remote Health 6 (3): 595.

Den Dulk, C.J., Van de Stadt, H. and Vliegen, J.M. (1992) 'Een nieuwe maatstaf voor stedelijkheid: de omgevingsadressendichtheid' [A new measure for degree of urbanization: the address density of the surrounding area], Mndstat bevolk 7: 14-22. 
Verheij, R.A., Maas, J., Groenewegen, P.P. Urban-rural health differences and the availability of green space. European Urban and Regional Studies: 2008, 15(4), 307-316

Den Hertog, F.R.J., Bronkhorst, M.J., Moerman, M. and Van Wilgenburg, R. (2006) De gezonde wijk. Een onderzoek naar de relatie tussen fysieke wijkkenmerken enlichamelijke activiteit. Amsterdam: EMGO Instituut.

de Vries, S., Verheij, R.A., Groenewegen, P.P. and Spreeuwenberg, P. (2003) 'Natural Environments Healthy Environments?: an Exploratory Analysis of the Relationship Between Greenspace and Health', Environment and Planning A 35: 1717-31.

Frank, L., Kerr, J., Chapman, J. and Sallis, J. (2007) 'Urban Form Relationships with Walk Trip Frequency and Distance among Youth', American Journal of HealthPromotion. 21 (4): 305-11.

Giesbers, H. (2006) 'Reistijd naar ziekenhuis met afdeling spoedeisende hulp 2005' [Traveltime to hospital with ER facilities 2005], Volksgezondheid Toekomst Verkenning, nationale Atlas Volksgezondheid. Bilthoven: RIVM.

Goldberg, D.P. and Williams, P. (1988) The User's Guide tothe General Health Questionnaire. Windsor: NFER-Nelson.

Groenewegen, P.P., van den Berg, A.E., de Vries, S. and Verheij, R.A. (2006) 'Vitamin G: Effects of Green Space on Health, Well-being, and Social Safety', BMC PublicHealth 6: 149.

Health Council of the Netherlands and Dutch Advisory Council for Research on Spatial Planning, Nature and the Environment (2004) Nature and Health. The Influence of Nature on Social, Psychological and Physical Well-being. The Hague: Health Council of the Netherlands, RMNO. Accessed on 27 May 2008 at: [http://www.gr.nl/pdf.php?ID=1019\&p=1]. Archived by WebCite at:

[http://www.webcitation.org/ 5Y7iVCpyn].

Janssen-Janssen, S.M.A., van der Lucht, F., Otten, F.W.J., and Geurts, J.M.M. (2001) 'Verschillen in gezondheid tussen stedelijke en niet-stedelijke gebieden' [Differences in health between urban and rural areas], in F. van der Lucht and H. Verkleij (eds) Gezondheid in degrote steden [Health in cities], pp. 2932. Bilthoven: Bohn Stafleu Van Loghum.

Kaplan, R. and Kaplan, S. (1989) The Experience of Nature.A Psychological Perspective. Cambridge: Cambridge University Press.

Kruger, O., Aase, A. and Westin, S. (1995) 'Ischaemic Heart Disease Mortality among Men in Norway: Reversal of Urban-Rural Health Differences between 1966 and 1989', Journal of Epidemiological andCommunity Health 49 (2): 271-6.

Larson, A., Bell, M. and Young, A.F. (2004) 'Clarifying the Relationships between Health and Residential Mobility', Soc.Sci.Med. 59 (10): 2149-60.

Levin, K.A. (2003) 'Urban-Rural Differences in Selfreported Limiting Long-term Illness in Scotland', Journal of Public Health and Medicine 25 (4): 295-302.

Lewis, G., David, A., Andreasson, S. and Allebeck, P.(1992) 'Schizophrenia and City Life', The Lancet 340: pp. 137-40.

Lindert, H. v., Droomers, M., and Westert, G.P. (2004) Een kwestie van verschil: verschillen in zelfgerapporteerdeleefstijl, gezondheid en zorggebruik Utrecht/Bilthoven: NIVEL, RIVM.

Maas, J., Verheij, R.A., Groenewegen, P.P., de Vries, S. and Spreeuwenberg, P. (2006) 'Green Space, Urbanity, and Health: How Strong is the Relation?', Journal ofEpidemiology and Community Health 60 (7): 587-92.

Milgram, S. (1970) 'The Experience of Living in Cities', Science 167: 1461-8.

Mitura, V. and Bollman, R. (2004) 'Health Status and Behaviours of Canada's Youth: a Rural-

Urban Comparison', Rural and Small Town Canada AnalysisBulletin 5 (3): 1-22.

Norman, P., Boyle, P. and Rees, P. (2005) 'Selective Migration, Health and Deprivation: a Longitudinal Analysis', Soc.Sci.Med. 60 (12): 2755-71.

NRC-Handelsblad (2006) Pendrecht wekt Franse jaloezie[Pendrecht makes French jealous].

Rotterdam: NRC-Handelsblad.

Otten, F. and Frenken, F. (2006) 'Minder gezond in de stad' [Less healthy in the city], in N. Van Nimwegen and I. Esveldt (eds) Bevolkingsvraagstukken in Nederland anno 2006: grote steden in demografisch perspectief, pp. 267-82. Den Haag: NIDI.

Pedersen, C.B. and Mortensen, P.B. (2006) 'Urbanization and Traffic Related Exposures as Risk Factors for Schizophrenia', BMC.Psychiatry 6: 2.

Population Division of the Department of Economic and Social Affairs of the United Nations (2007) 'World Population Prospects: the 2004 Revision'. New York: UN Population Division of the Department of Economic and Social Affairs. Available at: [http://www.un.org/esa/population/publications/WP P2004/WPP2004_Volume3.htm.].

Schellingerhout, R. and Van Campen, C. (2006) 'Gezondheid en zorg' [Hēealth and healthcare], in A. Steenbekkers, C. Simon and V. Veldheer (eds) Thuis op het platteland, pp. 151-76. Den Haag: Planbureau, Sociaal en Cultureel. Statistics Netherlands (2007) Average minutes per week total physical activity by urbanization rate. Available at: www.statline.nl. 
Verheij, R.A., Maas, J., Groenewegen, P.P. Urban-rural health differences and the availability of green space.

European Urban and Regional Studies: 2008, 15(4), 307-316

Ulrich, R.S. (1993) 'Biophilia, Biophobia and Natural Landscapes,' in S.R. Kellert and E.O. Wilson (eds) The Biophelia Hypothesis, pp. 75-137. Washington DC: Island Press.

Van Lenthe, F.J., Martikainen, P. and Mackenbach, J.P. (2007) 'Neighbourhood Inequalities in Health and Health-related Behaviour: Results of Selective Migration?', Health and Place 13: 123-37.

Verheij, R.A. (1996) 'Explaining Urban-Rural Variations in Health: a Review of Interactions between Individual and Environment.', Soc. Sci. Med, 42: 923-35.

Verheij, R.A., van de Mheen, H.D., De Bakker, D.H., Groenewegen, P.P. and Mackenbach, J.P.

(1998) 'Urban-Rural Variations in Health in the Netherlands: Does Selective Migration Play a Part?', Journal of Epidemiology and Community Health, 52 (8): 487-93.

Westert, G.P., Schellevis, F.G., De Bakker, D.H., Groenewegen, P.P., Bensing, J.M. and Van der Zee, J. (2005) 'Monitoring Health Inequalities through General Practice: the Second Dutch National Survey of General Practice', European Journal of Public Health 15 (1): 59-65.

Wilson, E.O. (1984) Biophilia. Harvard, MA: President and fellows of Harvard College, Wirth, L. (1938) 'Urbanism as a Way of Life', American Journal of Sociology 84: 1201-31. 
Verheij, R.A., Maas, J., Groenewegen, P.P. Urban-rural health differences and the availability of green space. European Urban and Regional Studies: 2008, 15(4), 307-316

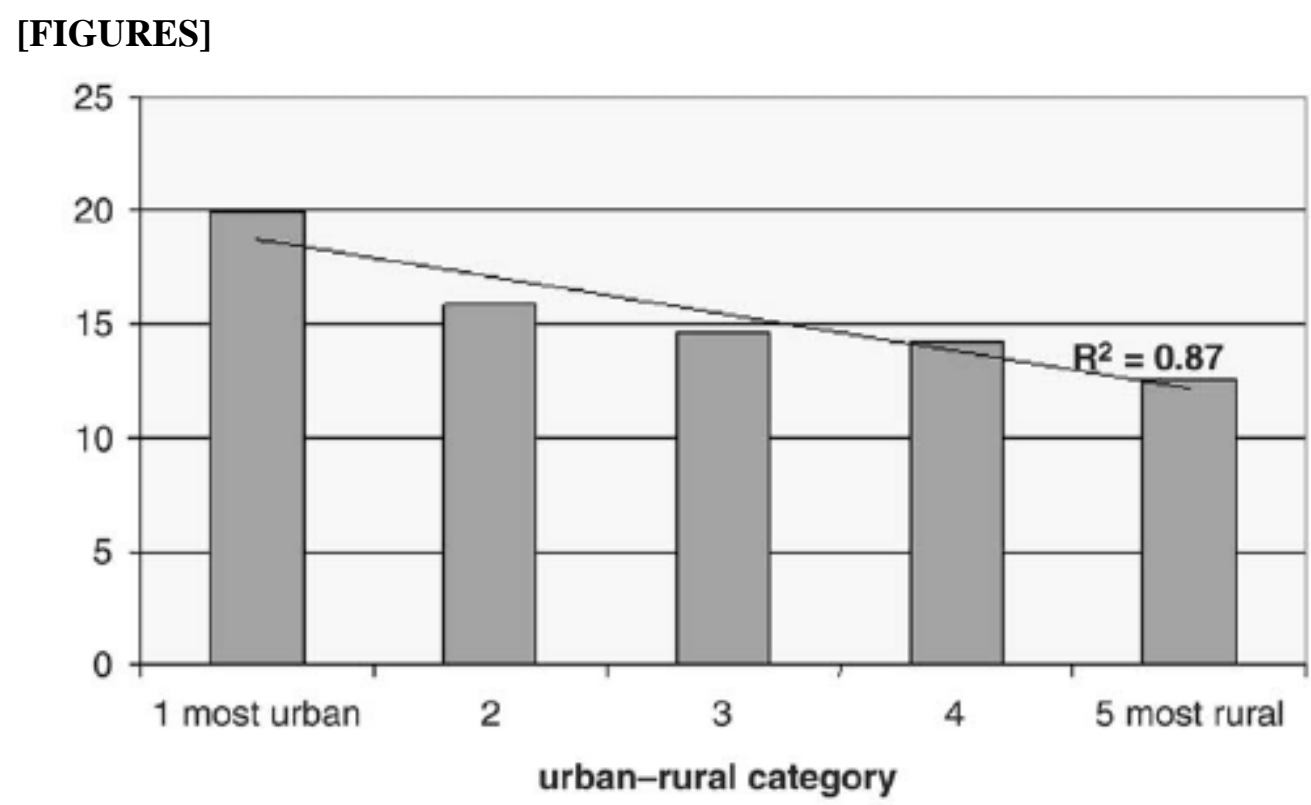

Figure 1 Percentage of the population with health status less than good, by urban-rural category in the Netherlands, 2001 $(\mathrm{N}=12.699)$

Source: Second Dutch National Survey of General Practice, Westert et al. (2005).

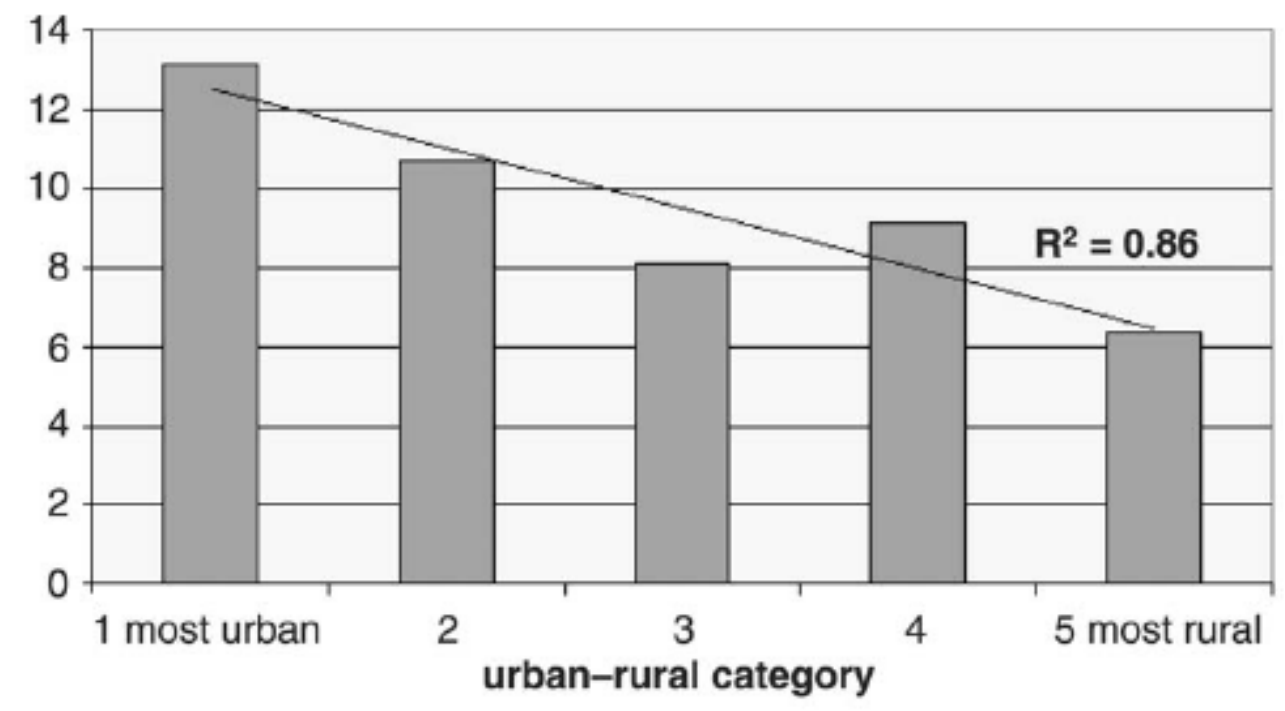

Figure 2 Percentage of the population with a mental illness (GHQ > 5) by urban-rural category in the Netherlands, 2001 $(\mathrm{N}=12.699)$

Source: Second Dutch National Survey of General Practice, Westert et al. (2005). 
Verheij, R.A., Maas, J., Groenewegen, P.P. Urban-rural health differences and the availability of green space. European Urban and Regional Studies: 2008, 15(4), 307-316

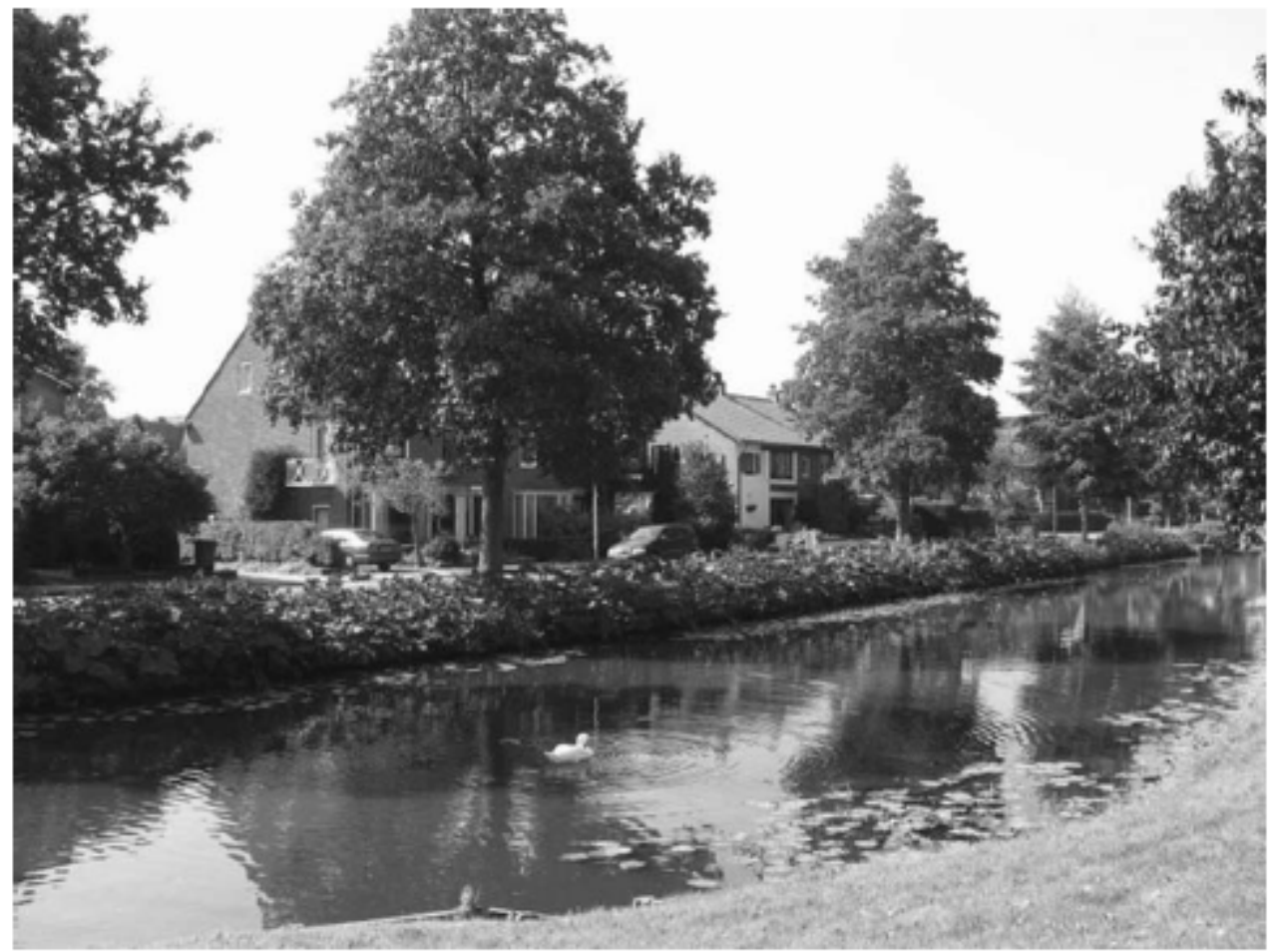

Figure 3

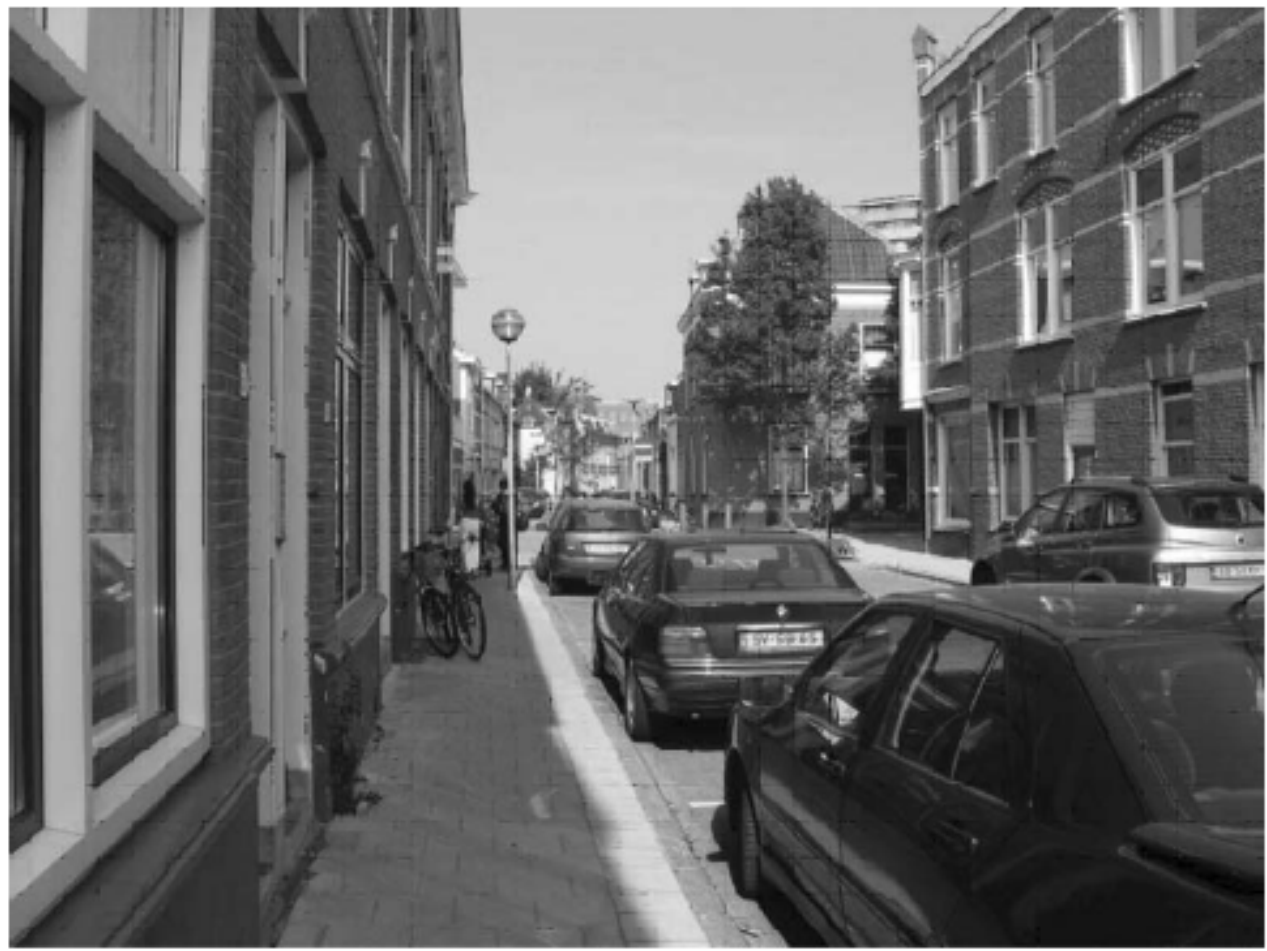

Figure 4 